Proc. Indian Acad. Sci. (Earth Planet. Sci.), Vol. 98, No. 3, October 1989, pp. 279--286.

(C) Printed in India.

\title{
Solar activity and radiative flux divergence in the tropical middle atmosphere
}

\author{
K MOHANAKUMAR \\ School of Marine Sciences, Cochin University of Science and Technology, Fine Arts Avenue, \\ Cochin 682016 , India \\ MS received 5 December 1988; revised 27 July 1989

\begin{abstract}
Results of a study on radiative net flux divergence at various heights of the middle atmosphere $(15-80 \mathrm{~km})$ over the tropical station, Thumba $\left(8^{\circ} \mathrm{N}, 77^{\circ} \mathrm{E}\right)$, India, for a period of 12 years from 1971 to 1982 using M-100 rocket data are reported. Over Thumba mesospheric net flux divergence occurs during the descending phases and flux convergence takes place during the ascending phases of the solar cycle. The net flux divergence in middle stratosphere seems to have quasi-biennial variations. The total net flux divergence during a 11-year solar cycle is found to be highly negative in the mesosphere and strongly positive in the upper stratosphere, representing the heat source and sink regions in the middle atmosphere.
\end{abstract}

Keywords. Solar activity; net flux divergence; middle atmosphere.

\section{Introduction}

The view that solar activity influences weather and climate has been a subject of debate among scientists for more than a century. No viable theory and plausible physical mechanism have been presented so far to explain how solar activity can affect meteorological phenomena. But before looking into a direct relationship between sun and the weather, it is useful to find the influence of solar activity on middle atmospheric changes and then couple these changes to the tropospheric weather.

There is a growing evidence from both theory and observation that the middle atmosphere does play a role in the general circulation and radiative balance of the lower atmosphere. The most obvious link between the middle and lower atmosphere is the direct exchange of radiation between the stratosphere and troposphere due to emission and absorption of radiation by various trace gases (Andrews et al 1987). Changes in the distribution of any of these may influence the temperature structure in both the troposphere and middle atmosphere and hence may possibly influence the general circulation in both regions. In this note we examine the possible part played by the solar activity on these linkages.

The determination of the radiation characteristics of the middle atmosphere assumes importance in order to study the radiative interactions between the middle atmosphere and troposphere (Kondratyev 1965). The radiant heat exchange in the atmosphere is connected with the changes in air temperature (Kondratyev 1972) which must be taken into account when investigating the thermal region of the middle atmosphere associated with the changes in solar activity. Earlier studies (Ramakrishna and Seshamani 1973; Mohanakumar 1985, 1988; Von Cossart and Taubenheim 1987; 
Chanin et al 1987) have shown that the temperature in the mesosphere has a strong positive response to the solar activity and that it has only weak or negative relation in the stratosphere. Recent studies (Labitzke 1987; Labitzke and Van Loon 1988; Labitzke and Chanin 1988) show that when the temperature data are stratified into east or west phase of the equatorial quasi-biennial oscillation (QBO) in stratospheric zonal wind, significant relationships are obtained between the temperature in the stratosphere and troposphere and solar activity. The purpose of the present study is to find the changes in radiative net flux at various levels in the middle atmosphere associated with the variations in solar activity in the 11-year cycle.

\section{Method of computation of net flux divergence}

Consider a plane parallel atmosphere confined between altitudes $z$ and $z+\mathrm{d} z$. Let $F^{\dagger}$ and $F^{\downarrow}$ represent the upward and downward radiative fluxes, respectively, integrated for all wavelengths in the layer. As the thickness $\mathrm{d} z$ approaches zero, the energy absorbed per unit volume in the layer is given by the net integrated vertical radiative flux divergence for all wavelengths and can be represented as (Kondratyev 1965)

$$
\partial F / \partial z=-\rho C_{p}(\partial T / \partial t)
$$

where $F$ is the net integrated radiative flux $\left(F^{\dagger}-F^{\downarrow}\right), \partial T / \partial z$ is the variation of temperature $T$ in the layer per unit time, $C_{p}$ is the specific heat at constant pressure and $\rho$ is the mean density of the layer. To determine the vertical net flux divergence at any layer of the atmosphere, the heating rate $(\partial T / \partial t)$ of that layer must be calculated. The heating rate for any given layer of the atmosphere is computed as

$$
\partial T / \partial t=\left(T_{2}-T_{1}\right) /\left(t_{2}-t_{1}\right)
$$

where $T_{2}$ and $T_{1}$ are the temperatures at times $t_{2}$ and $t_{1}$ respectively. The annual and seasonal mean values of temperatures are used in this study to compute the heating rate at various levels of the middle atmosphere.

When the net vertical flux divergence $\partial F / \partial z>0$, the radiative heat causes a cooling of air temperature (i.e., $\partial T / \partial t<0$ ), while at $\partial F / \partial z<0$ indicate a warming of air temperature $(\partial T / \partial t>0)$. The case when $\partial F / \partial z=0$ appears to describe the radiative equilibrium at a given layer, so that the heat inflow is zero $(\partial T / \partial t=0)$.

The temperature and density data used in the present study for the computation of net flux divergence are obtained from weekly $\mathrm{M}-100$ rocket soundings over Thumba $\left(8^{\circ} \mathrm{N}, 77^{\circ} \mathrm{E}\right)$ for a full 11 -year solar cycle period from 1971 to 1982 . Yearwise and seasonwise (summer-time-June, July and August, and winter-time-December, January and February) net flux divergences are then computed at various heights of the middle atmosphere, between 15 and $80 \mathrm{~km}$. The computed net flux changes are then compared with the changes in solar activity in the 11-year cycle using the $\mathrm{F} 10.7 \mathrm{~cm}$ solar radio flux as the solar activity parameter. An attempt has also been made in this study to find the mean annual radiative net flux distribution in the middle atmosphere, by computing the mean annual flux variations. 


\section{Results and discussion}

Changes in radiative net flux at each $5 \mathrm{~km}$ layers of the tropical middle atmosphere between 15 and $80 \mathrm{~km}$ during a 11-year solar cycle (1971-1982) are illustrated in figure 1. Rate of change of $\mathrm{F} 10.7 \mathrm{~cm}$ solar radio flux for the same period is shown in

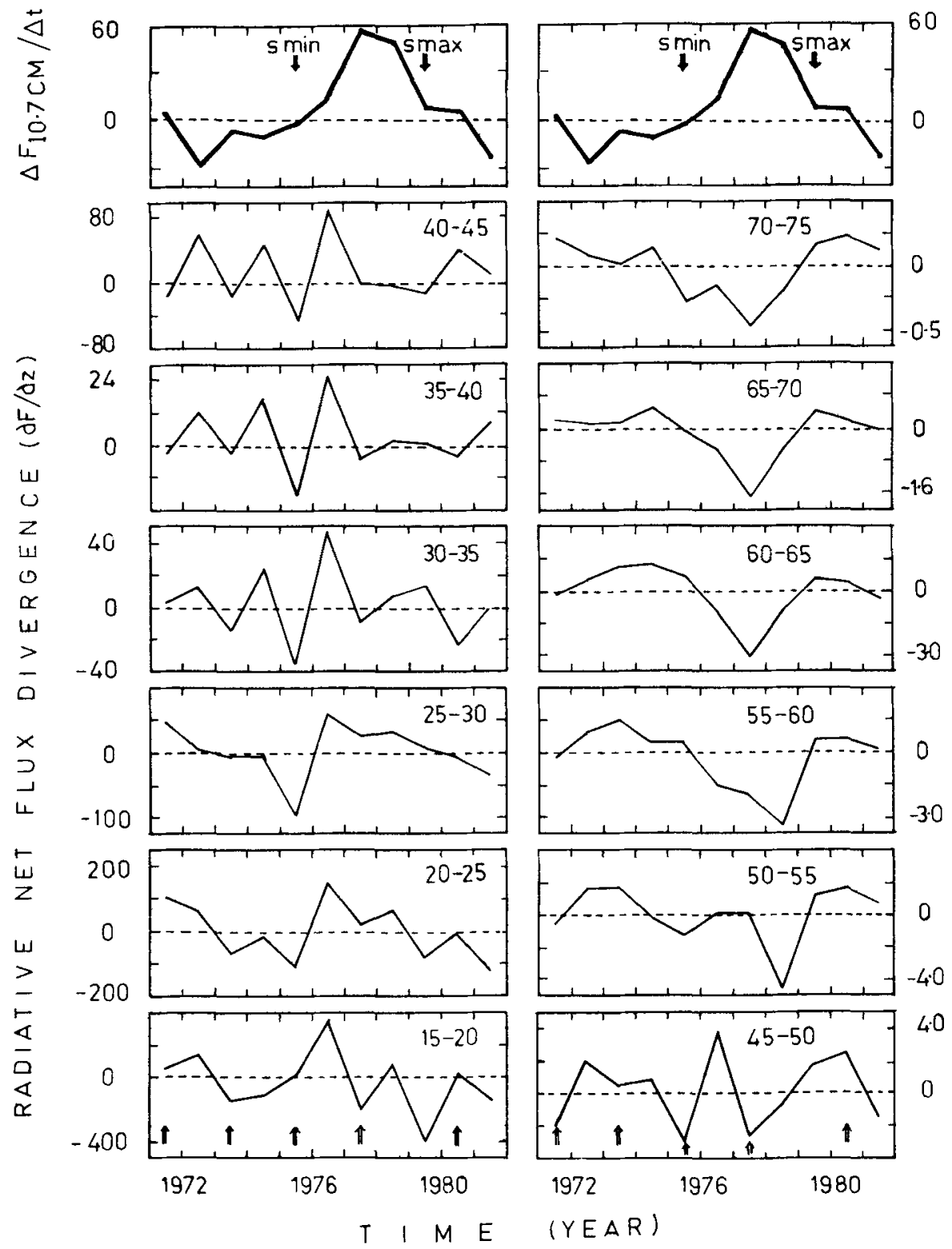

Figure 1. Radiative net flux changes in the tropical middle atmosphere associated with solar activity. 
the upper part of figure 1. The upward directed arrows in the bottom part of figure 1 indicate the period of equatorial quasi-biennial west wind maximum. Also, the horizontal dotted line in each box of the figure illustrates the level of radiative equilibrium.

It can be seen that the net flux changes in stratospheric layers show large fluctuations, whereas in mesospheric layers the variations are regular. Except for sudden change in flux noted during 1975-76, the layer between 25 and $30 \mathrm{~km}$ shows a zone of radiative equilibrium. Quasi-biennial type net radiative flux variations are quite distinct in the upper stratospheric layers, with radiative flux convergences associated with the period of equatorial quasi-biennial west wind maximum and flux divergences associated with the period of east wind maximum. During the period of peak variations in solar flux, the upper part of the stratosphere is found to be in radiative equilibrium.

Radiative flux divergence in mesospheric layers shows an out-of-phase relation with changes in solar radio flux. Associated with the period of higher changes in solar activity, the layers in the mesosphere register a zone of strong radiative flux convergence and associated with the period of lower changes a zone of strong radiative flux divergence is noted. This indicates that larger variations in solar radio flux result in warming and small variations in solar radio flux cause cooling in mesosphere. Peak values of the rate of change in solar activity are well associated with the period of strong convergence in net radiative flux in the mesosphere.

Figure 2 illustrates the variations in net radiative flux in the tropical middle atmophere during the period of a 11-year solar cycle extending from 1971 to 1982. The changes in net radiative flux in the mesosphere show specific trend with radiative flux divergence occurring during the descending phase and the flux convergence taking place during the ascending phase of the solar cycle. The radiative flux changes in the middle mesosphere and lower stratosphere show somewhat out-of-phase relationship.

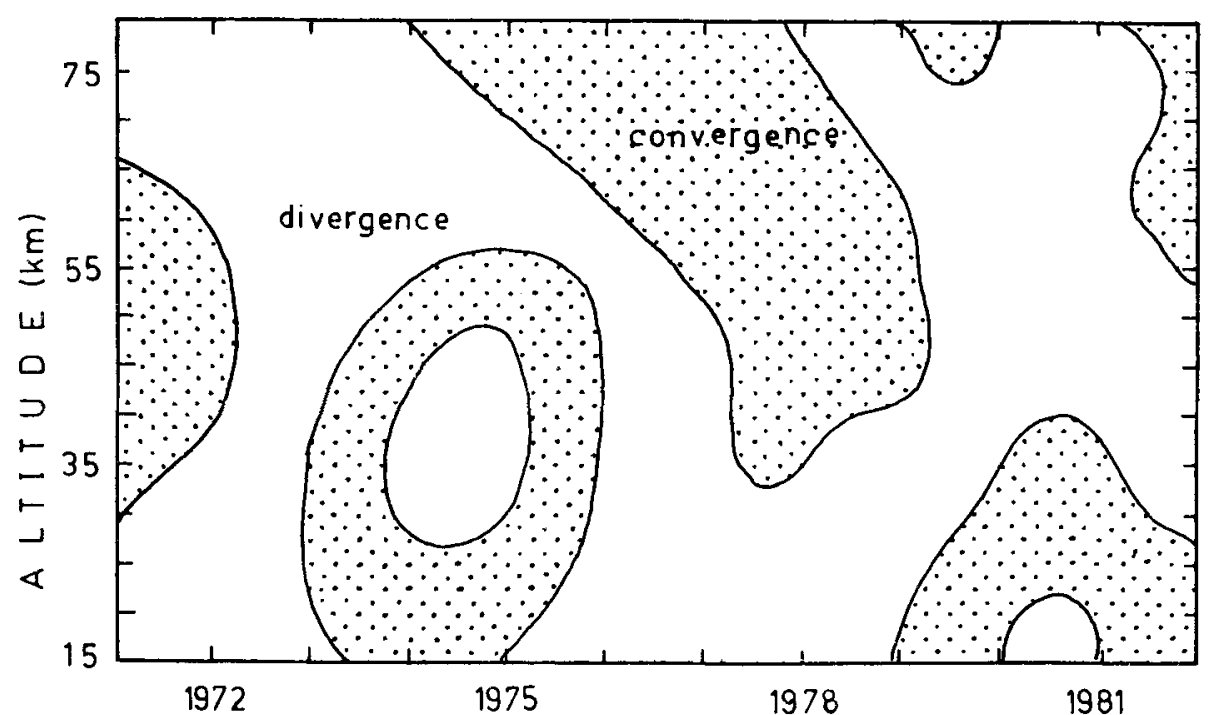

Figure 2. Time-height cross section of radiative flux divergence in the middle atmosphere. 


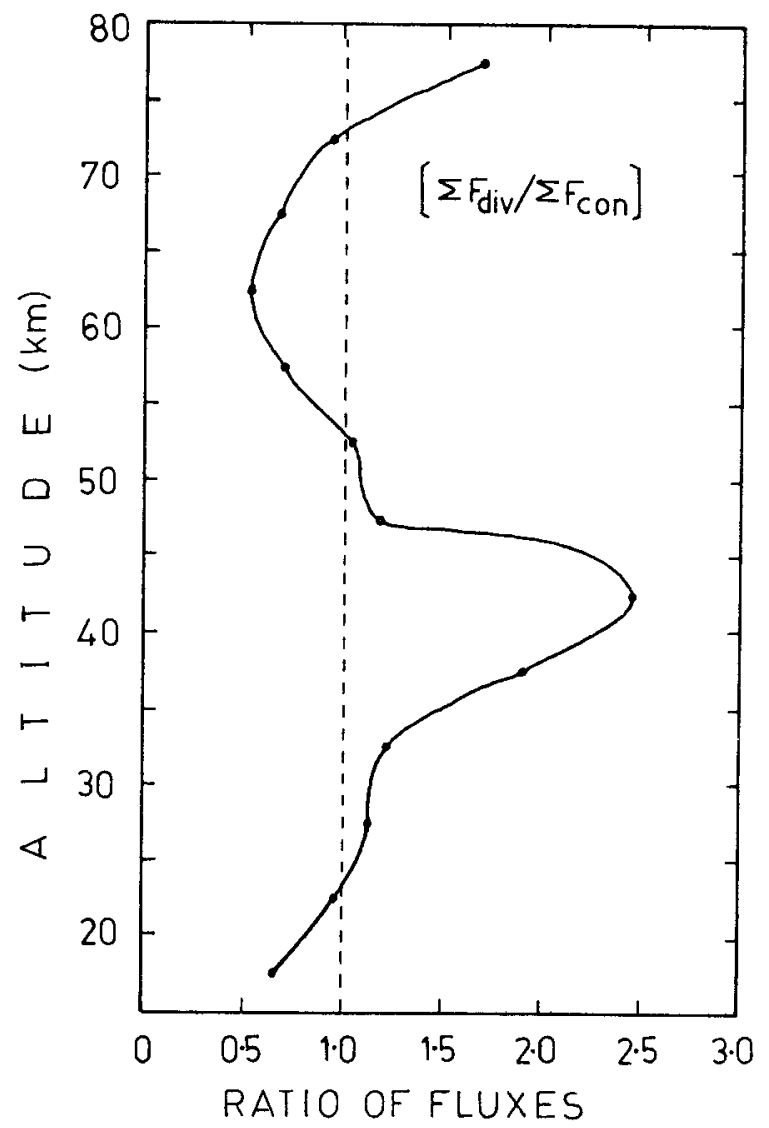

Figure 3. Vertical distribution of the ratio of the sum of radiative flux divergence to convergence over a solar cycle.

The net flux convergence and divergence alternate frequently in the middle stratosphere showing nearly quasi-biennial type of variations.

In order to find the general behaviour of the net flux variations in the middle atmosphere for the entire period of the 11-year cycle, the ratio of the sum of the net flux divergence to the flux convergence is computed at each $5 \mathrm{~km}$ levels of the middle atmosphere during the 12-year period and is shown in figure 3 . The convergence in radiative flux occurs below $23 \mathrm{~km}$ altitude. The ozone-enriched zone of the tropical middle atmosphere (between 23 and $33 \mathrm{~km}$ ) registers a region of radiative equilibrium during the period of a 11-year solar cycle. In other words, the convergence and divergence in radiative fluxes over a solar cycle balance each other in the middle stratosphere $(25-35 \mathrm{~km})$. Strong divergence in radiative flux in the $40-45 \mathrm{~km}$ layer indicates a zone of radiative cooling. On the other hand, layers in the mesosphere show zones of active flux convergence which represent areas of radiative heating. The maximum convergence in net radiative flux is noted in the $65-70 \mathrm{~km}$ region. A zone of dominant radiative flux divergence exists above $73 \mathrm{~km}$, which may be extending into the lower thermosphere.

According to the nature of net radiative flux variations, the tropical middle atmosphere comprises of three zones. The mesosphere, where the radiative flux 


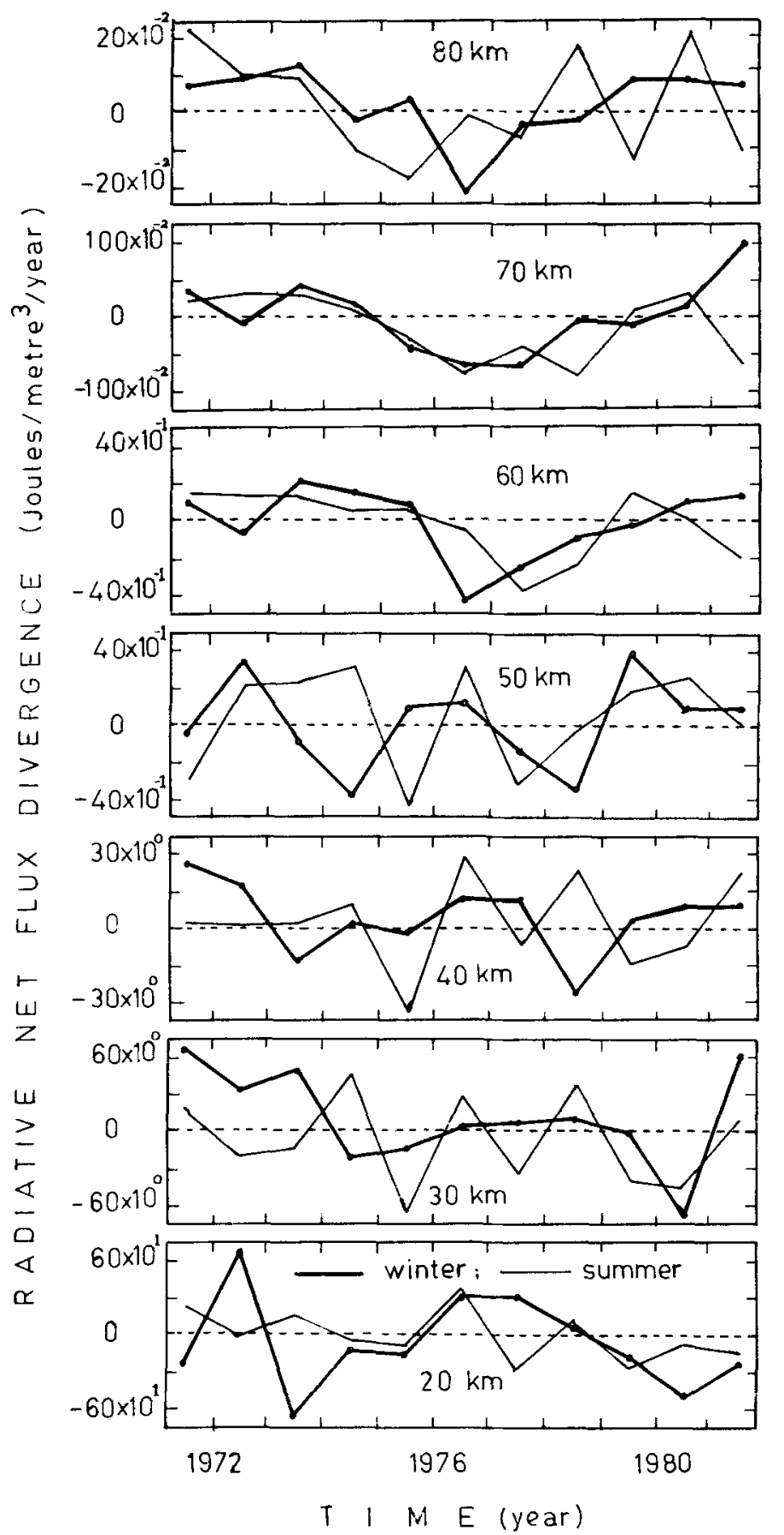

Figure 4. Seasonal changes in radiative flux in the middle atmosphere.

convergence plays a dominant role and produces a zone of higher rates of heating can be considered as a heat source region. Strong divergence in radiative flux in the upper stratosphere $(35-50 \mathrm{~km})$ produces a zone of cooling which can be taken as the 


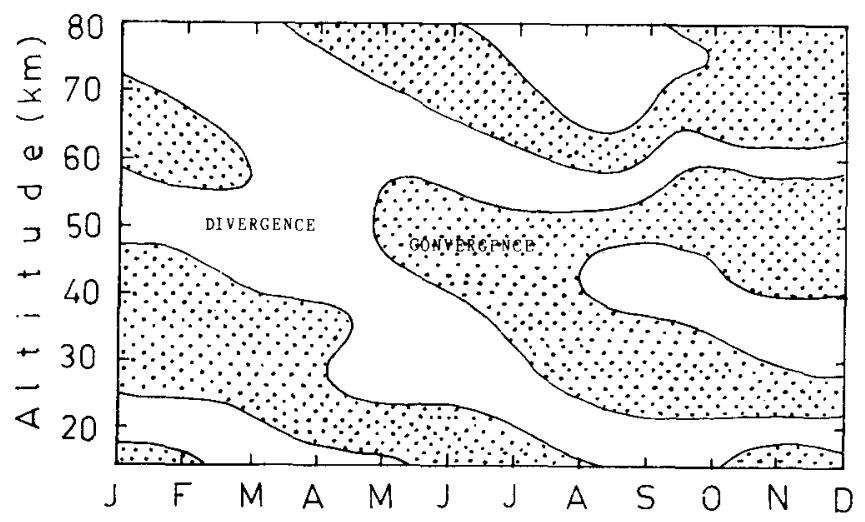

Figure 5. Annual distribution of radiative flux divergence/convergence in middle atmosphere.

heat sink region. The ozone abundant middle part of the stratosphere acts in a state of radiative equilibrium. Thus the response of the middle atmosphere to solar variability differs with altitude.

Summer-time (June, July and August) and winter-time (December, January and February) changes in radiative flux in the middle atmosphere for the 12-year period 1971 to 1982 are illustrated in figure 4 . Summer-time flux variations are comparatively consistent with height in the stratosphere, and show biennial type of flux variations with flux convergences associated with the west wind maximum and flux divergence associated with the east wind maximum. During both seasons, flux changes show specific variations in the mesosphere with divergences in the net flux being associated with the descending phase and convergences in flux being associated with the ascending phase of the solar cycle. Upper mesosphere $(70-80 \mathrm{~km})$ again shows large flux variations in net radiative flux during the 12 -year period.

Mean annual changes in radiative net flux in the tropical middle atmosphere are illustrated in figure 5 . The mean annual changes in radiative flux with altitude show a downward propagation of radiative energy through the middle atmosphere. The speed of this propagation shows a linear decrease with altitude at the rate of $6 \mathrm{~km} /$ month in mesosphere and $4 \mathrm{~km} /$ month in stratosphere. These alternating radiative flux convergence and divergence regimes descend from mesospheric levels to stratosphere.

\section{Conclusion}

The study on radiative net flux changes in the tropical middle atmosphere associated with a 11-year solar cycle showed that in mesosphere, convergence in flux occurs during the period of increasing solar activity and divergence in flux takes place during the period of decreasing solar activity. The radiative flux changes in middle mesosphere and lower stratosphere are found to be inversely related. Quasi-biennial variation in radiative flux is observed in the middle stratosphere with flux convergence during the westerly phase and flux divergence during the easterly phase of equatorial QBO of zonal wind. The sum of radiative flux changes during the period of a 11-year solar 
cycle shows strong divergence in radiative flux in mesosphere and convergence in flux in upper stratosphere, representing the heat source and sink regions in the middle atmosphere.

\section{Acknowledgement}

The author wishes to thank the two referees of this manuscript for their valuable suggestions and comments. The present study was carried out with financial support from the State Committee on Science, Technology and Environment, Kerala.

\section{References}

Andrews D G, Holton J R and Leovy C B 1987 Middle atmosphere dynamics (New York: Academic Press) p. 443

Chanin M L, Smires N and Hauchecorne A 1987 Long-term variations of the temperature of the middle atmosphere at mid-latitudes: Dynamical and radiative causes; J. Geophys. Res. 92 10933-10941

Kondratyev K Ya 1965 Radiative heat exchange in the atmosphere (Oxford: Pergamon Press) p. 517

Kondratyev K Ya 1972 Radiation processes in the atmosphere (W M O Tech. Rep. No. 309) p. 155

Labitzke K 1987 Sunspots, the QBO and the stratospheric temperature in the north polar regions; Geophys. Res. Lett. $14535-537$

Labitzke K and Chanin M L 1988 Changes in the middle atmosphere in winter related to the 11-year solar cycle; Ann. Geophys. 6 643-644

Labitzke K and Van Loon H 1988 Associations between the 11-year solar cycle, the QBO and atmosphere. Part I: the troposphere and stratosphere in Northern Hemispheric winter; J. Atmos. Terr. Phys. 50 197-206

Mohanakumar K 1985 An investigation on the influence of 11-year solar cycle on mesospheric temperature; Planet. Space Sci. 33 795-805

Mohanakumar K 1988 Response of an 11-year solar cycle on middle atmospheric temperature; Phys. Scr. 37 460-466

Ramakrishna S and Seshamani R 1973 The effect of solar activity on temperatures in the equatorial mesosphere; J. Atmos. Terr. Phys. 35 1631-1641

Von Cossart $\mathrm{G}$ and Taubenheim J 1987 Solar cycle and long period variations of mesospheric temperatures; J. Atmos. Terr. Phys. 49 303-307 